\title{
The Purification and Properties of Placental Histaminase
}

\author{
By J. K. SMITH \\ University Department of Clinical Chemistry, The Royal Infirmary, Edinburgh
}

(Received 26 May 1966)

\begin{abstract}
1. Histaminase was extracted from desanguinated human placentae and purified by salt fractionation, ion-exchange chromatography and gel filtration. The purest preparation was still contaminated with haptoglobin-methaemoglobin. 2. Histaminase activity was measured by the $o$-aminobenzaldehyde method of Holmstedt \& Tham (1959), Kapeller-Adler's (1951) test and a modified spectrophotometric indigodisulphonate test of greater sensitivity. 3. Unless contaminant metal ions were removed, enzymic activity on cadaverine, but not on histamine, fell during purification. When EDTA was added to the working buffers, a constant ratio between activities towards cadaverine and histamine was maintained throughout the later stages of purification, and activities towards the two substrates could not be separated by any of the highly resolving chromatographic analyses employed. 4. The purest preparation oxidized histamine, agmatine and benzylamine more slowly than the $\mathrm{C}_{4}-\mathrm{C}_{6}$ aliphatic diamines, but mixed-substrate experiments suggested that all these amines were substrates of histaminase. 5. The substrate and inhibitor specificities of placental histaminase were compared with those of related enzymes from other sources.
\end{abstract}

Extracts of hog kidney and human placenta catalyse the oxidative deamination of histamine and several aliphatic diamines, such as cadaverine (1,5-diaminopentane), according to the overall reation (Zeller, 1938):

$$
\mathrm{R} \cdot \mathrm{CH}_{2} \cdot \mathrm{NH}_{2}+\mathrm{H}_{2} \mathrm{O}+\mathrm{O}_{2} \rightarrow \vec{R} \cdot \overrightarrow{C H O}+\mathrm{NH}_{3}+\mathrm{H}_{2} \mathrm{O}_{2}
$$

Kapeller-Adler (1956a) considered that extracts from these organs contained enzymes specific for histamine and for the aliphatic diamines respectively, and called them 'histaminase' and 'diamine oxidase'. Other workers have since obtained highly purified enzyme preparations from hog kidney (Mondovì, Rotilio, Finazzi \& Scioscia-Santoro, 1964), pea seedlings (Hill \& Mann, 1964) and pig plasma (Buffoni \& Blaschko, 1964), and these preparations apparently contain single enzymes that catalyse the oxidative deamination of both histamine and the diamines. The Commission on Enzyme Nomenclature of the I.U.B. (1961) has accepted the view that these enzymes lack complete specificity and has named them diamine-oxygen oxidoreductase (deaminating) with trivial names diamine oxidase and histaminase (EC 1.4.3.6).

Because of the differences between the findings of Kapeller-Adler (1951) and of Mondovì et al. (1964) and Hill \& Mann (1964), it was decided to purify and reinvestigate the specificity of the enzyme or enzymes from human placenta responsible for the oxidative deamination of histamine and the aliphatic diamines. Earlier experiments on the substrate specificity of human placental histaminase used crude preparations of the enzyme (Zeller, 1938; Kapeller-Adler, 1951, 1956a; Lindahl, 1961). For comparison of activities on histamine and cadaverine after each stage of purification a single method of assaying histaminase activity on all substrates was ideally required, and the application of column-chromatographic fractionation procedures demanded a simple and sensitive method, suitable for the assay of numerous dilute effluents. Initially, the titrimetric indigo test devised by Kapeller-Adler (1951) was used, but this proved to be unsatisfactory, and a sensitive spectrophotometric modification of the indigo test was developed.

\section{MATERIALS AND METHODS}

\section{Materials}

Agmatine sulphate, diaminobutane dihydrochloride (putrescine), diaminopentane dihydrochloride (cadaverine), $o$-aminobenzaldehyde and neuraminidase (from Clostridium perfringens) were obtained from Sigma Chemical Co. Ltd., London, S.W. 6. Indigodisulphonate, histamine dihydrochloride, benzylamine hydrochloride, diaminoethane dihydrochloride, aminoguanidine disulphate, semicarbazide hydrochloride, hydroxylamine hydrochloride and phenylhydrazine hydrochloride were obtained from British Drug Houses Ltd., Poole, Dorset. Isoniazid was supplied by 
Mann Research Laboratories, New York, N.Y., U.S.A., and diaminopropane dihydrochloride and diaminohexane dihydrochloride were from Eastman-Kodak Ltd., Liverpool. All inorganic reagents were A.R. grade.

\section{Column chromatography}

DEAE-cellulose (Sigma Chemical Co. Ltd.) had an exchange capacity of $1 \mathrm{~m}$-equiv./g., and cellulose phosphate (Whatman P-11) had a nominal exchange capacity of 7.4m-equiv./g. Sephadex G-200 (Pharmacia, Uppsala, Sweden) was allowed to swell in distilled water at $5^{\circ}$, under toluene, for several months before repeated decantation of fines. The gel bed was retained between two fixed porous piston heads in the LKB Recychrom recycling chromatography apparatus (LKB Producter AB, Stockholm, Sweden). Sample application and elution were carried out in an upwards direction with the aid of a peristaltic pump.

\section{Starch-gel electrophoresis}

This was carried out by the method of Smithies (1955) for $20 \mathrm{hr}$. at a field strength of $10 \mathrm{v} / \mathrm{cm}$. at $5^{\circ}$. Horizontal slices of the completed gel were stained for protein with Nigrosine ( $0.1 \%$ in water) and for haptoglobin-methaemoglobin with the following solution: $0.3 \mathrm{M}$-acetate buffer, pH4.6, $35 \mathrm{ml}$.; $o o^{\prime}$-dianisidine, $35 \mathrm{mg}$.; ethanol, $35 \mathrm{ml}$.; water, $80 \mathrm{ml}$; $\mathrm{H}_{2} \mathrm{O}_{2}$ (100 vol.), $1 \mathrm{ml}$. The histaminase content of macerated serial sections of the gel was determined by the method of Holmstedt \& Tham (1959) (see below). Histaminase was located in the intact gel by incubating the gel in a solution having the same composition as test solutions in the latter method.

\section{Estimation of protein}

The protein concentration of enzyme solutions was estimated from the extinction at $280 \mathrm{~m} \mu$, an $E$ value of 1.0 being expressed as a protein concentration of $1 \mathrm{mg} . / \mathrm{ml}$. EDTA (0.1 mM) was included in all buffer solutions used in the purification of histaminase and in activity measurements.

\section{Measurement of histaminase activity}

Indigodisulphonate method. The procedure used was identical with the modification by Kapeller-Adler \& MacFarlane (1963) of the original method of KapellerAdler (1951), except that 0.1 mM-EDTA was added to the buffer, and concentrations of substrates found to be required to provide optimum conditions for placental histaminase activity were different (cadaverine, $1.14 \mathrm{~mm}$; histamine, 0.136 mm). Kapeller-Adler (1956b) considered that the oxidative deamination of 1 mole of substrate was accompanied by the production of 1 mole of $\mathrm{H}_{2} \mathrm{O}_{2}$, which stoicheiometrically oxidized part of the indigodisulphonate present, the excess of dye being estimated by titration with dilute $\mathrm{KMnO}_{4}$ solution at the end of incubation.

In the present work, difficulty was experienced in discerning the equivalence point in the presence of different substrates and coloured proteins (cf. Burkard, 1954) with the result that activity measurements below 5 permanganate units (P.U.) were subject to errors of more than
$10 \%$. Activity was linearly related to enzyme concentration only up to 15 P.U. The decolorization of the dye did not start immediately on addition of enzyme and substrate solutions but was delayed for $4-8 \mathrm{hr}$. while $\mathrm{H}_{2} \mathrm{O}_{2}$ accumulated in the solution. The extent of dye oxidation after $24 \mathrm{hr}$. incubation was sometimes much greater than could be accounted for by the oxidation of all the substrate initially present. For these reasons, a modified procedure was adopted.

Modified spectrophotometric indigodisulphonate method. Histaminase solution $(0.2 \mathrm{ml}$.) was added to $2.6 \mathrm{ml}$. of $0.067 \mathrm{M}$-phosphate buffer (Sörensen, 1909), pH6.8, containing $0.1 \mathrm{~mm}-E D T A$, and $1 \mathrm{ml}$. of $0.287 \mathrm{~mm}$-indigodisulphonate. The solution was warmed to $37^{\circ}$ and the reaction started by the addition of $0.2 \mathrm{ml}$. of substrate. The final concentration of each substrate used was $2.28 \mathrm{~mm}$ for cadaverine or putrescine, and $34 \mu \mathrm{M}$ for histamine. The solutions were incubated for $24 \mathrm{hr}$., and extinction was measured in a Unicam SP.500 spectrophotometer at $610 \mathrm{~m} \mu$, the wavelength of maximum extinction of indigodisulphonate $\left(\epsilon 1.73 \times 10^{4} \mathrm{~mole}^{-1} \mathrm{~cm} .^{-1}\right)$. The reference cuvette contained a more-dilute $(36 \mu \mathrm{M})$ solution of the dye in the same buffer. One spectrophotometric unit (S.U.) of histaminase activity was the amount required to produce a decrease of 1.0 in the $E$ value in $24 \mathrm{hr}$; in practice, the concentration of the enzyme was adjusted so that the measured decrease was in the range $0 \cdot 02-0 \cdot 15 \mathrm{~S}$.U. Indigodisulphonate was very slowly decolorized by diamines in the presence of EDTA, and controls were incubated without enzyme rather than without substrate. The concentration of protein in the assay was usually very low (less than $1 \mu \mathrm{g} . / \mathrm{ml}$. for highly purified histaminase solutions) and a correction for the extinction of coloured proteins had to be applied only when assaying the crude placental extract.

The S.D. of six replicate assays, determined at four dilutions of histaminase from 0.03 to $0.15 \mathrm{~S}$.U., was less than $\pm 5 \%$ of the mean in each case. Within this range, activity was linearly related to enzyme concentration. The linear range was of the same order for histaminase solutions at all stages of purification, and with either histamine or cadaverine as substrate. Oxygenation before incubation did not significantly increase the rate of reaction, but increased the non-enzymic oxidation of indigodisulphonate in the presence of cadaverine. Results were also less reproducible after oxygenation, and it was not adopted.

As in Kapeller-Adler's (1951) method, more dye was decolorized than could be accounted for by the stoicheiometric oxidation of substrate and production of $\mathrm{H}_{2} \mathrm{O}_{2}$. This was due to a secondary oxidative mechanism of indigodisulphonate decolorization, requiring oxygen and products of the enzymic reaction, but the extent of this secondary reaction could not be estimated. For this reason, spectrophotometric units could not be converted into international units of activity. Although the incubation of the test solutions resulted in the immediate oxidation of histamine (detectable by the fluorimetric method of Shore, Burkhalter \& Cohn, 1959) and production of $\mathrm{H}_{2} \mathrm{O}_{2}$ (detectable by the oxidation of ${ }^{\prime} o^{\prime}$-dianisidine in the presence of peroxidase), the decolorization of indigodisulphonate was delayed for 2-4hr., after which it proceeded linearly for $24 \mathrm{hr}$. The 'lag period' in dye oxidation was not due to contaminant reducing agents in the components of the solution. It was shown that no appreciable dye oxidation occurred until a certain amount of enzymic activity had 


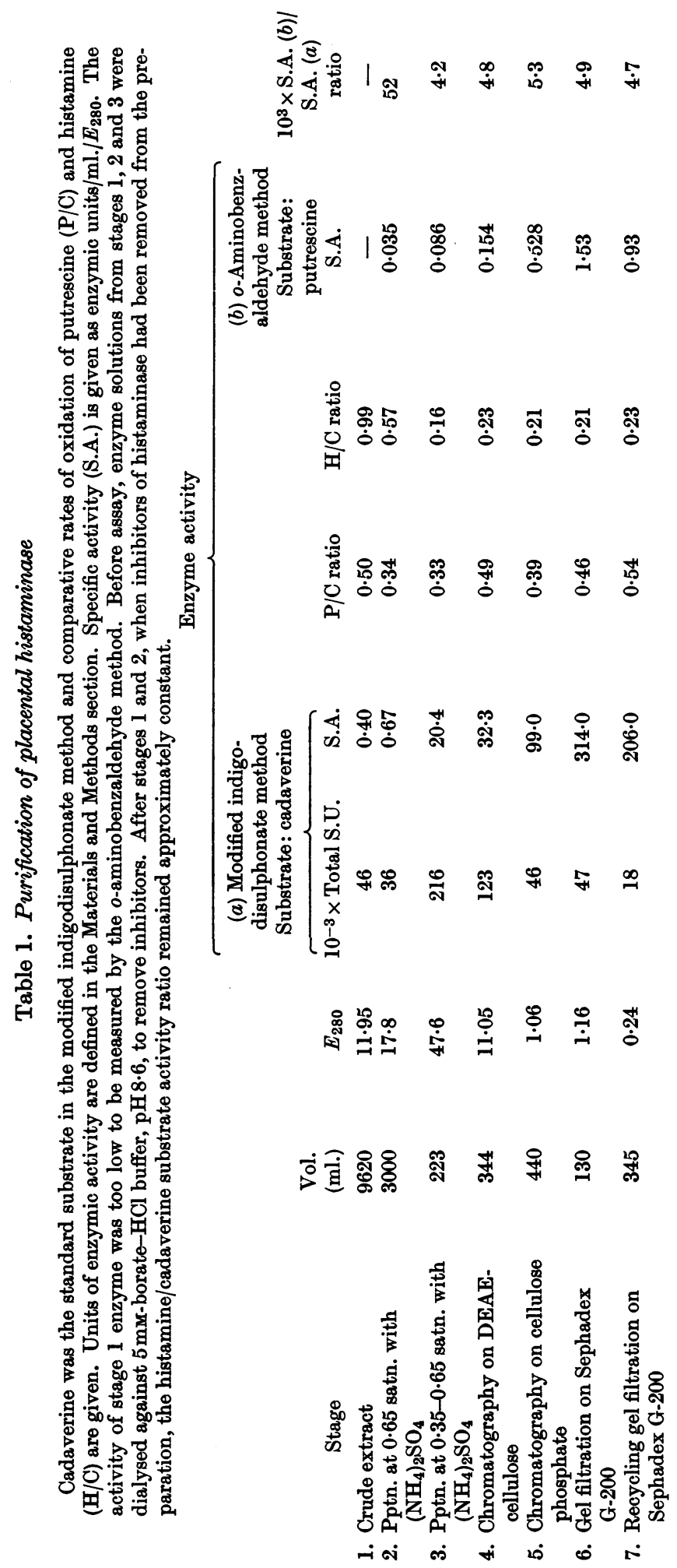


taken place and, presumably, a critical concentration of $\mathrm{H}_{2} \mathrm{O}_{2}$ had formed. Where an experiment demanded that the initial velocity of histaminase activity be known, this was measured as the rate of decolorization of the dye in the period of linear velocity immediately after the initial delay.

o-Aminobenzaldehyde method. Histaminase solution was incubated at $37^{\circ}$ with $2.5 \mathrm{~mm}$ - 0 -aminobenzaldehyde and $1.0 \mathrm{~mm}$-putrescine in a total volume of $4 \mathrm{ml}$. in $0.067 \mathrm{M}$-phosphate buffer (Sörensen, 1909), pH6.8, containing 0.1 mMEDTA, as described by Holmstedt \& Tham (1959). Controls containing all components except substrate were incubated in the same way. The increase in extinction of the tests at $430 \mathrm{~m} \mu$ was measured at the end of the incubation period. Initial velocity was not maintained for more than $1 \mathrm{hr}$., but tests were sometimes incubated for longer periods when precise measurement of initial velocity was not required. One unit of activity in this method was defined as the amount of enzyme required to produce an increase in the $E$ value of $1 \cdot 0 \mathrm{in} 1 \mathrm{hr}$.

\section{RESULTS}

\section{Purification of placental histaminase}

For the purification of the enzyme, a combination of ammonium sulphate precipitation and fractionation on columns of DEAE-cellulose, cellulose phosphate and Sephadex was used. The purification attained at each stage is shown in Table 1. The procedure finally adopted was as follows.

Stage 1. Normal human placentae were obtained within $30 \mathrm{~min}$. of delivery, the umbilical cord was cut off at the base and the amnion was removed. The vascular bed of each placenta was perfused from the foetal side with $\mathbf{0 . 9} \%$ sodium chloride for $\frac{1}{2}-1 \frac{1}{2} \mathrm{hr}$., with 3-91. of solution, until the maternal and foetal surfaces were pink. The chorion and insoluble blood clots were cut away and the remaining tissue was stored at $-15^{\circ}$. Five organs prepared in this way were thawed and ground in an electric mincer, and the mince was then homogenized twice with 2 vol. of sodium chloride solution for $30 \mathrm{~min}$. After each extraction, the mince was filtered through muslin and the pooled filtrates were centrifuged. The mince and extract were kept cool throughout all these operations, and the next stage was started within $12 \mathrm{hr}$. of extraction. Desanguination of the placentae at stage 1 was always incomplete, and the preparation remained heavily contaminated with haemoproteins.

Stage 2. The filtrate from stage 1 was brought to 0.65 saturation with ammonium sulphate and the precipitate was collected and dissolved in $0 \cdot 02 \mathrm{~m}$-phosphate buffer, $\mathrm{pH} 6 \cdot 8$. Stage 2 resulted in little purification, but served to concentrate the preparation and protect it from bacterial degradation, which otherwise set in rapidly, even at $0-5^{\circ}$.

Stage 3. Ammonium sulphate was added to give
0.35 saturation, and the precipitated protein discarded. More ammonium sulphate was added to the filtrate to give 0.65 saturation. This suspension could be stored at $0-5^{\circ}$ for at least 6 months without loss of activity. The precipitate was collected and dissolved in $5 \mathrm{~mm}$-borate-hydrochloric

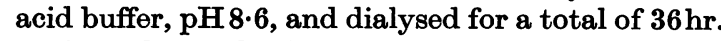
against three 51. changes of the same buffer. A comparison of the specific activities of stage 2 and stage 3 enzyme as measured by the two methods showed that the second precipitation stage removed non-diffusible substances (possibly peroxidases) that inhibited histaminase activity measured by the modified indigodisulphonate method, but not by the 0 -aminobenzaldehyde method.

Stage 4. The solution from stage 3 was applied to a column $(5 \mathrm{~cm} . \times 80 \mathrm{~cm}$.) of DEAE-cellulose, previously equilibrated with $5 \mathrm{~mm}$-borate-hydrochloric acid buffer, pH 8.6, and washed in with 21 . of the same buffer containing $0.08 \mathrm{M}$-sodium chloride; red haemoproteins were eluted. Elution of histaminase, together with brown haemoproteins, was effected with $0 \cdot 17 \mathrm{M}$-phosphate buffer, pH 6.8, containing $0.5 \mathrm{M}$-sodium chloride; $20 \mathrm{ml}$. fractions were collected, and those containing most histaminase activity (Fig. $1 a$ ) were pooled and dialysed for $24 \mathrm{hr}$. at $4^{\circ}$ against three 31 . changes of $0.02 \mathrm{M}$ phosphate buffer, pH 6.8. Stage 4 did not resolve histaminase from haemoproteins as effectively as small-scale chromatography at the same $\mathrm{pH}$ under a shallow salt gradient, but a very large protein load could be processed quickly without great dilution of the preparation.

Stage 5. The solution from stage 4 was applied to a column $(5 \mathrm{~cm} . \times 80 \mathrm{~cm}$.) of cellulose phosphate, previously equilibrated with $0.02 \mathrm{M}$-phosphate buffer, pH 6.8, and washed in with $300 \mathrm{ml}$. of the same buffer. A linear gradient of $0-3 \mathrm{M}$-sodium chloride over 41. in equilibrating buffer was used to elute histaminase. Histaminase activity in the breakthrough peak was rejected, and the fractions of highest specific activity (Fig. 1b), eluted between about $0.2 \mathrm{M}$ - and $0.4 \mathrm{M}$-sodium chloride, were pooled. Stage 5 partly resolved histaminase from methaemoglobin; the loss of enzyme by association with the latter protein in the breakthrough peak could be diminished by dividing the sample load between two columns, but the resulting increase in volume of the effluent was not offset by significant improvements in yield and specific activity.

Stage 6. The pooled fractions from stage 5 were concentrated to $20 \mathrm{ml}$. by osmosis against Carbowax (polyethylene glycol, mol.wt. 20000; Union Carbide Ltd., London, W.1), and pumped upwards through a column $(3 \mathrm{~cm} . \times 100 \mathrm{~cm}$.) of Sephadex G-200. The buffer used in packing and elution of the column was $5 \mathrm{~mm}$-borate-hydrochloric acid, pH 8.6, containing $0 \cdot 1 \mathrm{M}$-sodium chloride. Hist- 


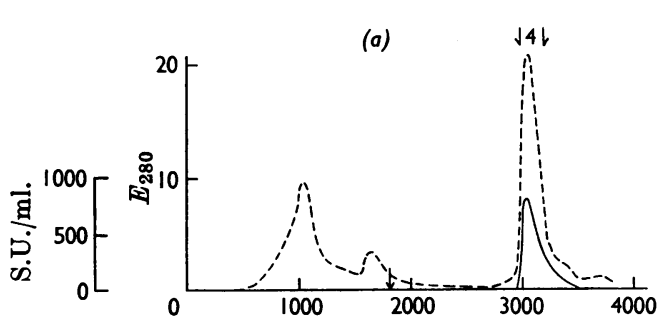

Vol. of effluent (ml.)

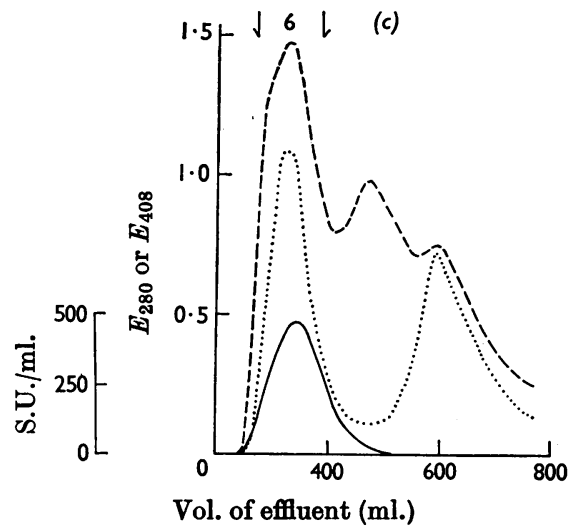

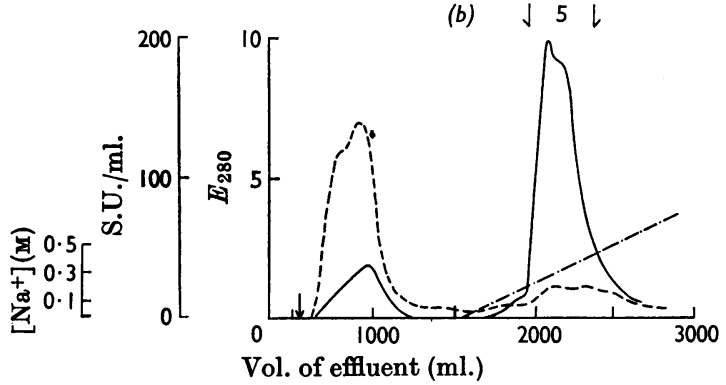

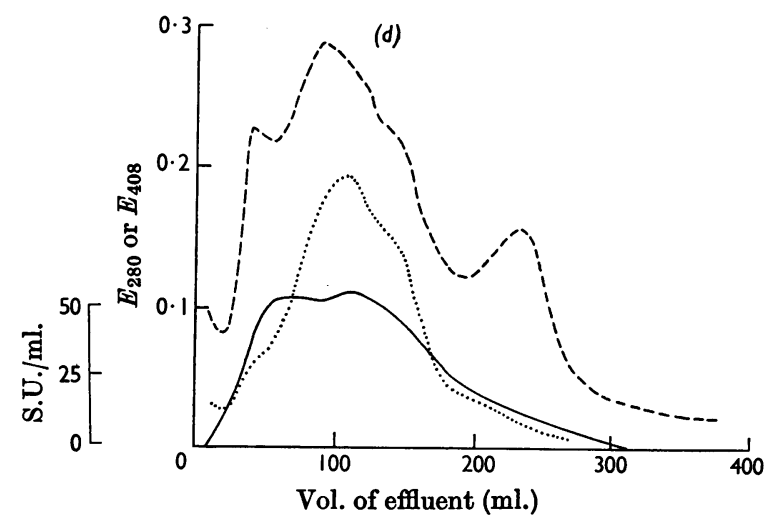

Fig. 1. Chromatographic elution patterns at different stages during the purification of placental histaminase. (a) Enzyme from stage 3 of the scheme was added to a column of DEAE-cellulose in 5 mM-borate-HCl buffer, pH 8.6; after development with 21. of $0.08 \mathrm{M}-\mathrm{NaCl}$ in buffer, histaminase was eluted with $0.17 \mathrm{M}-$ phosphate buffer, pH6.8, containing $0.5 \mathrm{M}-\mathrm{NaCl}$, starting at $\downarrow$. (b) Enzyme from the previous stage was applied to a column of cellulose phosphate in $0.02 \mathrm{M}$-phosphate buffer, $\mathrm{pH} 6.8$, and eluted under a gradient of $0-3 \mathrm{M}-\mathrm{NaCl}$ over 4l. of buffer, starting at $\downarrow$. (c) Enzyme from the previous stage was concentrated and filtered once through Sephadex G-200. (d) Enzyme from the previous stage was concentrated and recycled twice through Sephadex G-200. Details of conditions are given in the Materials and Methods section. - Histaminase activity (S.U.) ml.); - -- , protein $\left(E_{280}\right) ; \cdots$, , methaemoglobin and haptoglobin-methaemoglobin $\left(E_{408}\right) ;-\cdot-\cdot,\left[\mathrm{Na}^{+}\right]$in effluents (M).

aminase was eluted in the first of three protein peaks (Fig. 1c), and the fractions of highest specific activity were pooled. Stage 6 resolved histaminase from the last traces of haemoglobin and methaemoglobin, but the enzyme remained contaminated with haptoglobin-methaemoglobin and possibly some lipoprotein.

Stage 7. Stage 6 enzyme was concentrated to small volume against Carbowax, and $3 \mathrm{ml}$., containing $55 \mathrm{mg}$. of protein, was subjected to recycling gel filtration (Porath \& Bennich, 1963) on the column of Sephadex G-200 used in stage 6. The patterns of protein and histaminase activity eluted from the column after two cycles are shown in Fig. $1(d)$. Stage 7 , in which the preparation was exposed to room temperature for about 3 days, resulted in a decrease in specific activity of histaminase, but the effluent was purer than that from stage 6 in that fewer contaminating proteins were present, and this preparation was used in specificity studies. Recycling gel filtration resolved the enzyme from some minor contaminants, including the complex between methaemoglobin and the lower-molecularweight complexes of haptoglobin types 2-1 and 1-1. The most-active fractions from stage 7 were concentrated and subjected to starch-gel electro-

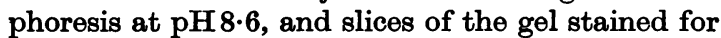
protein, haptoglobin-methaemoglobin and histaminase. All bands developing in the protein stain could be identified as haptoglobin-methaemoglobins by the $o o^{\prime}$-dianisidine reaction. Histaminase activity was spread across the entire region occupied by the protein bands, and no single protein band corresponding to histaminase could be discerned. The spreading of histaminase activity was not due simply to diffusion of the histaminase stain, since narrow serial sections of the gel, cut along the path of migration immediately after electro- 
phoresis, showed a comparable diffuse pattern of histaminase activity.

Further purification. Many attempts were made to resolve histaminase from its last contaminants by exploiting possible differences in their electrical properties over the entire $\mathrm{pH}$ range in which the enzyme is stable. Experiments with other ionexchangers, attempted modification of the haptoglobin contaminants with neuraminidase and preparative electrophoresis on starch blocks at pH8.6 were unsuccessful. By elution of stage 6 enzyme from DEAE-cellulose at $\mathrm{pH} 5 \cdot 5$, under a shallow salt gradient, histaminase could be separated from contaminant haptoglobin complexes, but the enzyme was inactivated by up to $95 \%$. This inactivation was not reversible by change in $\mathrm{pH}$ or the addition of possible coenzymes.

Effect of EDTA. After stages 1 and 2, when inhibitors of histaminase had been removed from the preparation, the histamine/cadaverine substrate activity ratio remained approximately constant (Table 1). The substrate activity ratio for the immediate homologues, putrescine and cadaverine, showed variations of the same order of magnitude. If EDTA was omitted from the buffers used in the purification scheme and in activity measurements, the putrescine/cadaverine substrate activity ratio varied from one placental preparation to another, and between successive stages, and the histamine/ cadaverine substrate activity ratio increased after stage 1, until almost no activity on cadaverine could be detected after stage 4. This virtual loss of activity on cadaverine, which could be reversed by the addition of EDTA, was attributed to the variable concentration of metal ions in different placental extracts, and the reagents added to them.

\section{Properties of the purified enzyme}

Determination of $K_{m}$. The determination of $K_{m}$ for the activity of histaminase on different substrates was handicapped by the lack of a suitable assay method applicable to all substrates. An attempt was made to measure $K_{m}$ for three substrates by the modified indigodisulphonate method, by using the rate of dye oxidation during the linear phase as an approximation to the initial velocity of the enzyme-substrate reaction.

The concentration of histamine giving maximal activity in this method was $20-40 \mu \mathrm{M}$; higher concentrations resulted in significantly lower activities. No substrate optima were observed for cadaverine and putrescine, up to $6 \mathrm{~mm}$. Although there was no direct evidence that the rate of indigodisulphonate oxidation was a reliable measure of initial rates of substrate oxidation, data for these substrates showed a linear relationship between [S]/v and [S] (where [S] is the substrate concentration and $v$ the 'initial' rate of dye oxidation). The apparent $K_{m}$ values for cadaverine and putrescine were of the same order, $0.2 \mathrm{~mm}$. The results for histamine (except those at greater-than-optimum concentrations) showed a linear relationship between $1 /[\mathrm{S}]$ and $1 / v$, and an apparent $K_{m}$ of $6 \mu \mathrm{M}$ was calculated.

The more direct $o$-aminobenzaldehyde method was used to determine $K_{m}$ for putrescine. An optimum of activity between $0.5 \mathrm{~mm}$ - and $1.0 \mathrm{~mm}$ putrescine was observed; an apparent $K_{m}$ of $0.07 \mathrm{~mm}$ was derived from the linear plot of $1 / v$ against $1 /[\mathrm{S}]$ for substrate concentrations less than $0.5 \mathrm{~mm}$.

Effect of $\mathrm{pH}$. The rate of activity of histaminase was measured by the modified indigodisulphonate method in phosphate buffers (Sörensen, 1909) of $\mathrm{pH}$ values from 5.6 to 8.0 (measured at room temperature) in the presence of $0.1 \mathrm{~mm}$-EDTA and near-optimum concentrations of several substrates. Rates of indigodisulphonate oxidation during the linear phase were measured, as an approximation to the initial velocity of the enzyme-substrate reaction. The $\mathrm{pH}$ optimum of a model reaction, in which enzyme solution was replaced by $0.05 \mu \mathrm{mole}$ of synthetic hydrogen peroxide, was measured simultaneously. The $\mathrm{pH}$ optimum for the action of histaminase on putrescine was measured, in the

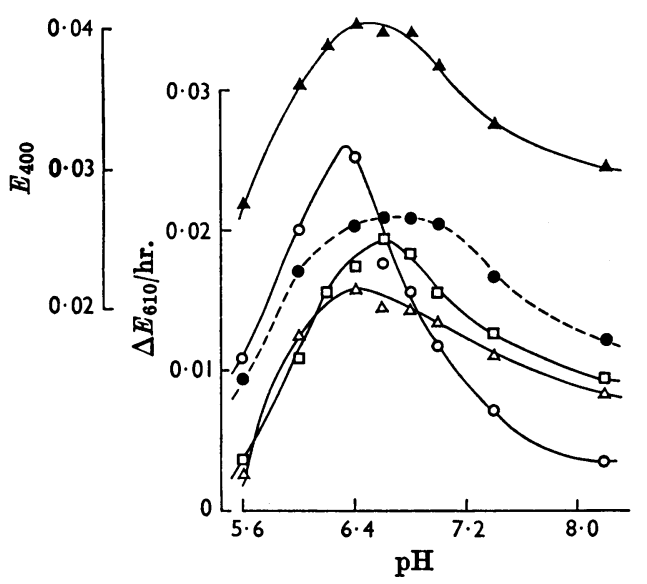

Fig. 2. Dependence of histaminase activity on $\mathrm{pH}$. The rate of histaminase activity was measured in phosphate buffers of $\mathrm{pH}$ values $5 \cdot 6$ to $8 \cdot 2$, as described in the text. The top curve (A) was obtained by using the o-aminobenzaldehyde method with putrescine as substrate. The curves with open symbols were obtained by using the modified indigodisulphonate method: 0 , cadaverine; $\Delta$, putrescine; $\square$, histamine. The concentration of enzyme, from stage 7 of the purification, varied with the substrate used. The broken line ( $)$ shows the pH-dependence of a non-enzymic model reaction measured in the same buffers, in which $0.05 \mu$ mole of synthetic $\mathrm{H}_{2} \mathrm{O}_{2}$ oxidized indigodisulphonate in the presence of cadaverine. 
same range of buffers, by the 0 -aminobenzaldehyde method; the results are compared in Fig. 2. Curves obtained by the modified indigodisulphonate method showed different $\mathrm{pH}$ optima for cadaverine, putrescine and histamine. The curves obtained for putrescine by the two methods were similar. The pH-dependence of the non-enzymic oxidation of indigodisulphonate by synthetic hydrogen peroxide in the presence of cadaverine was distinct from that of the enzymic oxidation of cadaverine, in the modified indigodisulphonate method.

Substrate specificity. The rates of placental histaminase (stage 7) activity on a number of diamines are compared in Table 2. Because the linear phase of indigodisulphonate oxidation was delayed for slightly different periods in the presence of different substrates, the velocities of dye oxidation during the linear phase were measured, rather than the total extinction change after $24 \mathrm{hr}$. incubation. The rate of oxidative deamination of the homologous aliphatic diamines by histaminase increased from $\mathrm{C}_{2}$ to $\mathrm{C}_{5}$, and decreased again at $\mathbf{C}_{6}$. Histamine and agmatine were oxidized at about the same rate as 1,3-diaminopropane, but benzylamine was oxidized only very slowly.

Substrate competition. Since some diamines were oxidized only very slowly, compared with the $\mathbf{C}_{4}-\mathbf{C}_{6}$ aliphatic diamines, the ability of the former to compete with near-saturating concentrations of putrescine for the active centre of histaminase was tested in mixed-substrate experiments. Stage 7 enzyme was incubated with each substrate alone, and with an equimolar mixture of putrescine and the substrate, by using the modified indigodisulphonate method. Extinction changes after $24 \mathrm{hr}$. incubation are shown in Table 3. 1,2-Diaminoethane, histamine and agmatine, which had

Table 2. Relative rates of oxidation of amines by highly purified placental histaminase (modified indigodisulphonate method)

The concentration of each substrate was $2 \cdot 28 \mathrm{~mm}$, and $0.2-1.0 \mathrm{ml}$. of appropriately diluted enzyme from stage 7 of the purification scheme was used. The rate of indigodisulphonate decolorization was measured during the linear phase.

\section{Substrate}

1,2-Diaminoethane

1,3-Diaminopropane

1,4-Diaminobutane (putrescine)

1,5-Diaminopentane (cadaverine)

1,6-Diaminohexane

Histamine

Agmatine

Benzylamine
Comparative rate $($ cadaverine $=100)$

5
23
54
100
40
23
17
5

been oxidized much less rapidly than putrescine in Table 2, appeared to compete with putrescine for the active centre of histaminase.

Since benzylamine was oxidized much more slowly than putrescine (Table 2), more-direct methods were used in investigating the possibility that these two substrates could compete with each other for the same enzyme. The oxidation of benzylamine to benzaldehyde by purified histaminase, in the absence and presence of the test solutions, was measured by extinction changes at $250 \mathrm{~m} \mu$ (Tabor, Tabor \& Rosenthal, 1954). Test solutions containing histaminase and substrates $(2.28 \mathrm{~mm})$ in a total volume of $4 \mathrm{ml}$. in $0.067 \mathrm{M}-$ phosphate buffer, pH 6.8, and control solutions without substrate, were incubated for $24 \mathrm{hr}$. and substrate was added to the controls immediately before extinction measurements were made (Table 4). Putrescine inhibited the oxidative deamination of benzylamine.

The 0 -aminobenzaldehyde method was also used to detect substrate competition between putrescine and less-rapidly oxidized amines. Extinction

Table 3. Substrate competition for highly purified placental histaminase (modified indigodisulphonate method)

Test solutions contained $2 \cdot 28 \mathrm{~mm}$-substrate, with and without the admixture of $2 \cdot 28 \mathrm{~mm}$-putrescine. The same volume of diluted enzyme from stage 7 of the purification scheme was used in each test, and the total extinction change after $24 \mathrm{hr}$. incubation recorded. Control solutions were incubated without enzyme. Histaminase activity is $87 \%$ of $V_{\max .}$ at $2.28 \mathrm{~mm}$-putrescine, and $92 \%$ of $V_{\max }$. at $4.56 \mathrm{~mm}$-putrescine.

$\begin{array}{lcc} & \begin{array}{c}2.28 \mathrm{~mm}-S u b- \\ \text { strate } \\ \text { alone }\end{array} & \begin{array}{c}2.28 \mathrm{~mm}-\mathrm{Sub}- \\ \text { strate }+2.28 \mathrm{~mm}- \\ \text { putrescine }\end{array} \\ \text { Putrescine } & 0.096 & 0.101 \\ \text { l,2-Diaminoethane } & 0.013 & 0.078 \\ \text { Histamine } & 0.038 & 0.050 \\ \text { Agmatine } & 0.029 & 0.039\end{array}$

Enzymic activity (S.U.)

Table 4. Competition between putrescine and benzylamine for highly purified placental histaminase

The conditions of assay are described in the text.

$\begin{array}{lc}\text { Substrate(s) } & \text { Activity } \\ \text { Benzylamine } & \left(\Delta E_{250} / 24 \mathrm{hr} .\right) \\ \text { Putrescine } & 0.425 \\ \text { Benzylamine+ putrescine } & 0.055 \\ & 0.255\end{array}$


changes after $\mathbf{3 h r}$. incubation are shown in Table $\mathbf{5}$. In all cases, the activity in the presence of both the substrate and putrescine was lower than in the presence of putrescine alone.

Inhibitor specificity. Table 6 summarizes the effect of increasing concentrations of histaminase inhibitors on the activity of the enzyme on putrescine, measured by both methods. Control assays, containing all components except enzyme, were incubated similarly. Indigodisulphonate was decolorized by some of the inhibitors, presumably by

Table 5. Substrate competition for highly purified placental histaminase (o-aminobenzaldehyde method)

The conditions of assay are given in the Materials and Methods section. The concentration of all substrates was $1.14 \mathrm{~mm}$, and the same volume of diluted enzyme from stage 7 was used in each test. Extinction changes after $3 \mathrm{hr}$. incubation were measured. The enzyme is saturated by $1.14 \mathrm{~mm}$-putrescine in this method, and is slightly inhibited by excess of substrate at $2 \cdot 28 \mathrm{~mm}$.

\begin{tabular}{|c|c|c|}
\hline \multirow[b]{2}{*}{ Substrate } & \multicolumn{2}{|c|}{ Activity $\left(\Delta E_{430} / 3 \mathrm{hr}\right.$.) } \\
\hline & $\begin{array}{l}1 \cdot 14 \mathrm{~mm}- \\
\text { Substrate } \\
\text { alone }\end{array}$ & $\begin{array}{c}1 \cdot 14 \mathrm{~mm}-\mathrm{Sub}- \\
\text { strate }+1 \cdot 14 \mathrm{~mm} \\
\text { putrescine }\end{array}$ \\
\hline Putrescine & 0.416 & 0.385 \\
\hline 1,2-Diaminoethane & 0.003 & $0 \cdot 244$ \\
\hline 1,3-Diaminopropane & 0.004 & $0 \cdot 340$ \\
\hline 1,6-Diaminohexane & $0 \cdot 253$ & 0.372 \\
\hline Histamine & 0.004 & 0.034 \\
\hline Agmatine & 0.026 & 0.067 \\
\hline Benzylamine & 0.004 & 0.365 \\
\hline
\end{tabular}

reduction, and an asterisk marks those tests in which this non-enzymic decolorization was very pronounced.

\section{DISCUSSION}

Comparison of assay methods. The measurement of $\Delta^{1}$-pyrroline produced by the oxidative deamination of putrescine (Holmstedt \& Tham, 1959) offers a more direct measure of histaminase activity than indigometric methods. However, both methods gave consistent results in most applications. After stage 3 of the purification scheme, when inhibitors specific for the indigometric method had been removed, the ratio of specific activities obtained by both assay methods remained constant. The pHdependence of histaminase activity on putrescine was the same, measured by either method, and the pH-dependence of a model reaction, in which indigodisulphonate was oxidized by synthetic hydrogen peroxide rather than by hydrogen peroxide produced enzymically, was distinct from the pH-dependence of the enzymic reaction on all three substrates. This finding supports the view that $\mathrm{pH}$ optima derived from indigometric data reflect the true $\mathrm{pH}$-dependence of the enzymesubstrate reactions. Enzymic activity in both assays was subject to inhibition by the same compounds, and often to a similar extent, although high concentrations of some inhibitors had specific effects on the secondary reactions measuring product formation. Different $K_{m}$ values were obtained by using the indigodisulphonate method and the 0 -aminobenzaldehyde method, the latter showing an inhibition of histaminase by high

\section{Table 6. Inhibitors of placental histaminase}

Diluted enzyme from stage 7 of the purification scheme was incubated with putrescine for 24 hr., under the conditions of the modified indigodisulphonate method $(a)$ and the 0 -aminobenzaldehyde method $(b)$, with and without the addition of inhibitors. Controls contained all components except enzyme solution.

Concn. of inhibitor......

\section{Inhibitor}

Sodium azide Ammonium chloride Sodium cyanide Aminoguanidine Isoniazid Diethyldithiocarbamate Semicarbazide Hydroxylamine
Inhibition (\%)

\begin{tabular}{|c|c|c|c|c|c|}
\hline \multicolumn{2}{|c|}{$1 \mathrm{~mm}$} & \multicolumn{2}{|c|}{$10 \mu \mathrm{M}$} & \multicolumn{2}{|c|}{$0 \cdot 1 \mu \mathrm{M}$} \\
\hline$(a)$ & (b) & (a) & (b) & (a) & (b) \\
\hline 0 & 0 & 2 & 0 & 2 & 0 \\
\hline 100 & 0 & 43 & 0 & 6 & 0 \\
\hline 33 & 98 & 0 & 0 & 6 & 0 \\
\hline 100 & 100 & 100 & 100 & 63 & 63 \\
\hline $44^{*}$ & 78 & 24 & 53 & 0 & 7 \\
\hline $100^{*}$ & 66 & 44 & 12 & 13 & 0 \\
\hline $100^{*}$ & 100 & 56 & 61 & 2 & 14 \\
\hline -* & 100 & 100 & 100 & 42 & 40 \\
\hline
\end{tabular}

* Controls severely affected by inhibitor. 
concentrations of putrescine that was not evident with the former. Placental histaminase may be usually sensitive to inhibition by the dihydroquinazolinium compounds formed in the test. The oxidative deamination of putrescine in both assay methods was inhibited by the same substrates (Tables 3 and 5).

Zeller (1965) has objected to indigometric histaminase assays on the grounds that histamine, but not the aliphatic diamines, catalyses the oxidation of indigodisulphonate by synthetic hydrogen peroxide, which otherwise proceeds very slowly, and he has attempted to explain in this way the failure of Kapeller-Adler \& MacFarlane (1963) to detect activity towards aliphatic diamines in highly purified hog-kidney histaminase. It was observed during the present work that the ratio of placental histaminase activities towards histamine and cadaverine remained constant, and less than unity, throughout purification of the enzyme. Moreover, even in model experiments in which synthetic hydrogen peroxide replaced enzymically produced hydrogen peroxide, cadaverine proved to be a much better catalyst of indigodisulphonate oxidation than histamine.

The modified indigodisulphonate test was adequate for the determination of histaminase concentrations, e.g. in chromatographic effluents, under strictly comparable conditions, but the lack of a close relationship between substrate oxidation and decolorization of the dye, especially during the early stages of the reaction, made indigometric tests unsuitable for precise kinetic studies. However, no adequate alternative method applicable to all substrates, and of comparable sensitivity, was available. The modified spectrophotometric indigodisulphonate test was about 50-fold more sensitive than the methods of Kapeller-Adler (1951) and Holmstedt \& Tham (1959).

Effect of metal ions. In the early stages of this work, substrate-specific inhibition of histaminase by metal ions almost led to the conclusion that at least two oxidative enzymes were present in the preparation. However, activity towards cadaverine was never detected in any fraction free from activity towards histamine.

It is possible that metal ions form co-ordinate bonds with the nitrogen atoms of diamines, and so alter their spatial and electronic configuration that the complexes are less readily accepted at the enzyme's active centre than the native diamines. This differential action of EDTA-reversible inhibitors of histaminase activity on its different substrates may explain the conflicting reports on the specificity of related enzymes. Kapeller-Adler \& MacFarlane (1963) and Uozomi, Nakahara, Higashi \& Sakamoto (1964) reported that preparations of hog kidney, originally active on both histamine and cadaverine, gradually lost activity towards cadaverine during purification, whereas Mondovi et al. (1964) achieved 1700-fold purification of hog-kidney histaminase without appreciable change in the histamine/cadaverine substrate activity ratio. With the exception of adaptive bacterial enzymes (Gale, 1942; Satake, Ando \& Fujita, 1953), specific for histamine and for putrescine, almost all other reports have suggested that plant and mammalian diamine oxidases oxidize histamine as well as diamines at an appreciable rate (e.g. Zeller, 1938, 1963; Hill \& Mann, 1964; Waton, 1956; Lindahl, 1961; Blaschko, Friedman, Hawes \& Nilsson, 1959).

$\mathrm{pH}$-activity curves. The $\mathrm{pH}$ optimum for the action of the enzyme on histamine supports the contention of Blaschko et al. (1959) that mammalian diamine oxidases attack the dicationic form of this substrate. Differences in pH optima are not due solely to the dissociation constants of the substrates' ionic groups; Kenten \& Mann (1952) found that the optima of pea-seedling diamine oxidase for cadaverine and putrescine were even more widely divergent than observed here with placental histaminase, although both diamines are completely dicationic below pH 8 .

Specificity of placental histaminase. Since histaminase was not completely purified, the substrates oxidized by even the purest preparation could not be assumed to have been oxidized by a single enzyme, without additional evidence. Although some of the diamines tested were oxidized much more slowly than the $\mathbf{C}_{4}-\mathrm{C}_{6}$ aliphatic diamines, mixed-substrate experiments presented in Tables 3-5 showed that the $\mathrm{C}_{2}$ and $\mathrm{C}_{3}$ aliphatic diamines, agmatine, benzylamine and histamine inhibited the oxidation of putrescine. Table 3 showed that nonadditive values of indigodisulphonate oxidation were obtained in the presence of an equimolar mixture of each substrate with a near-saturating concentration of putrescine. The results of Table 5, obtained by a more direct assay method, showed that other substrates (including benzylamine) inhibited the action of histaminase on an optimum concentration of putrescine; the fact that a twiceoptimum concentration of putrescine alone is inhibitory does not affect the conclusion that the other substrates were partially effective in replacing putrescine at the active centre of histaminase. The simplest explanation of these results is that each substrate competes with putrescine at the active centre of the same enzyme. The alternative possibility, that a number of distinct enzymes are present in the purest preparation, each specific for a single substrate and inhibited by other diamines, can be proved only by physical separation of these enzymes.

The evidence that histamine, cadaverine and 
putrescine are oxidized by the same enzyme is as follows:

(a) When precautions were taken to remove inhibitors from the preparation, the histamine/ cadaverine substrate activity ratio at successive stages of purification varied within the limits of experimental error, and did not tend to approach zero or infinity.

(b) Histamine markedly inhibited the oxidation of putrescine by histaminase as measured by two independent methods.

(c) Histamine oxidation could be estimated indigometrically or by a specific fluorimetric method in the presence of the purest preparation of histaminase. The extent of histamine oxidation could not be accounted for by contamination with any of the other enzymes known to metabolize histamine (see below).

The substrate and inhibitor specificities of placental histaminase resemble those of diamine oxidases from hog kidney and pea seedling (Zeller, 1963 ; Hill \& Mann, 1964). The enzyme differs from the benzylamine oxidase of human serum (McEwen, 1965) in its susceptibility to diethyldithiocarbamate and in the comparative rates of oxidation of histamine, benzylamine and putrescine, and it differs from mitochondrial monoamine oxidase (Blaschko, 1963) in its sensitivity to carbonyl reagents. During the present investigation, unsuccessful attempts were made to detect FAD, pyridoxal phosphate and copper by fluorimetric and spectrophotometric methods similar to those of Kapeller-Adler \& MacFarlane (1963) and Yamada \& Yasunobu (1962). The only evidence for the presence of copper or pyridoxal phosphate was the inhibition of the enzyme by diethyldithiocarbamate and carbonyl reagents, which are by no means specific in their action.

Another placental enzyme, imidazole $N$-methyltransferase, may be more important than histaminase in protecting the mother against foetal histamine (Bjüro, Lindberg \& Westling, 1964; Lindberg, Lindell \& Westling, 1963a,b; Lindberg, 1963a,b; Lindberg \& Törnqvist, 1966). This suggests that placental histaminase, which, as we have seen, can oxidize several aliphatic diamines faster than histamine, may be concerned with the destruction of these substances rather than histamine, though their function in normal metabolism is not as yet understood.

The author is indebted to Professor L. G. Whitby and Dr D. W. Moss for encouragement and criticism of this work, and gratefully acknowledges the provision of a Scholarship by the Medical Faculty of the University of Edinburgh. Professor R. J. Kellar kindly permitted the use of placentae from the Simpson Memorial Maternity Pavilion, Edinburgh.

\section{REFERENCES}

Bjüro, T., Lindberg, S. \& Westling, H. (1964). Acta obstet. gynec. scand. 43, 206.

Blaschko, H. (1963). In The Enzymes, 2nd ed., vol. 8, p. 337. Ed. by Boyer, P. D., Lardy, H. \& Myrbäck, K. New York: Academic Press Inc.

Blaschko, H., Friedman, P. J., Hawes, R. \& Nilsson, K. (1959). J. Physiol. 145, 384.

Buffoni, F. \& Blaschko, H. (1964). Proc. Roy. Soc. B, $161,153$.

Burkard, W. (1954). Contribution à l'Étude de l'Histaminase. Paris: R. Foulon et Cie.

Commission on Enzyme Nomenclature of the I.U.B. (1961). Report of the Commission on Enzyme Nomenclature of the I.U.B. Oxford: Pergamon Press Ltd.

Gale, E. F. (1942). Biochem. J. 36, 64.

Hill, J. M. \& Mann, P. J. G. (1964). Biochem. J. 91, 171.

Holmstedt, B. \& Tham, R. (1959). Acta physiol. scand. 45, 152.

Kapeller-Adler, R. (1951). Biochem. J. 48, 99.

Kapeller-Adler, R. (1956a). Ciba Found. Symp.: Histamine, p. 356. Ed. by Wolstenholme, G. E. W. \& O'Connor, C. M. London: J. and A. Churchill Ltd.

Kapeller-Adler, R. (1956b). Biochim. biophys. Acta, 22, 391.

Kapeller-Adler, R. \& MacFarlane, H. (1963). Biochim. biophys. Acta, 67, 542.

Kenten, R. H. \& Mann, P. J. G. (1952). Biochem. J. 50, 360.

Lindahl, K. N. (1961). Ark. Kemi, 16, 1.

Lindberg, S. (1963a). Acta obstet. gynec. scand. 42, Suppl. $1,3$.

Lindberg, S. (1963b). Acta obstet. gynec. scand. 42, Suppl. $1,26$.

Lindberg, S., Lindell, S. E. \& Westling, H. (1963a). Acta obstet. gynec. scand. 42, Suppl. 1, p. 35.

Lindberg, S., Lindell, S. E. \& Westling, H. (1963b). Acta obstet. gynec. scand. 42, Suppl. 1, p. 49.

Lindberg, S. \& Törnqvist, A. (1966). Acta obstet. gynec. scand. 45, 131.

McEwen, C. M. (1965). J. biol. Chem. 240, 2003.

Mondovi, B., Rotilio, J., Finazzi, A. \& Scioscia-Santoro, A. (1964). Biochem. J. 91, 408.

Porath, J. \& Bennich, H. (1963). Arch. Biochem. Biophys. Suppl. 1, 152.

Satake, K., Ando, S. \& Fujita, H. (1953). J. Biochem., Tokyo, 40, 299.

Shore, P. R., Burkhalter, A. \& Cohn, V. A. (1959). J. Pharmacol. 127, 182.

Smithies, 0. (1955). Biochem. J. 61, 628.

Sörensen, S. P. L. (1909). C.R. Lab. Carlsberg, 8, 1.

Tabor, C. W., Tabor, H. \& Rosenthal, S. M. (1954). J. biol. Chem. 208, 645.

Uozomi, K., Nakahara, I., Higashi, T. \& Sakamoto, Y. (1964). J. Biochem., Tokyo, 56, 601.

Waton, N. G. (1956). Brit.J. Pharmacol. 11, 119.

Yamada, H. \& Yasunobu, K. T. (1962). J. biol. Chem. $287,3077$.

Zeller, E. A. (1938). Helv. chim. Acta, 21, 880.

Zeller, E. A. (1963). In The Enzymes, 2nd ed., vol. 8, p. 314. Ed. by Boyer, P. D., Lardy, H. \& Myrbäck, K. New York: Academic Press Inc.

Zeller, E. A. (1965). Fed. Proc. 24, 766. 